\title{
Difference of Work Related Behaviors between Generation $X$ and Generation Y: A Study of Professionals of a Development Bank in Sri Lanka
}

Pathirage, U. K. ${ }^{1}$ and Weerasinghe, T. D. ${ }^{2}$

${ }^{1}$ University of Salford Manchester, United Kingdom

${ }^{2}$ Department of Human Resource Management, Faculty of Commerce and Management Studies, University of Kelaniya, Sri Lanka

${ }^{1}$ udenakp@gmail.com, ${ }^{2}$ dananjaya@kln.ac.lk

\begin{abstract}
Managing a multi-generation workforce today is becoming endlessly challenging, basically due to their different work related behaviors. In the recent literature, it is reported that further investigations are required for three work related behaviors of generations; work engagement, career development and teamwork, in banks, especially in developing countries. As a leading development bank in Sri Lanka, XYZ is unique in its multi-generation workforce consist of 2347 permanent employees as at 31 st July 2019 across the county. In the context, a gap is identified for such a study among two major generations; Gen X and Gen Y. Hence, bridging the gap in the context, and adding further evidence to the extant literature, this study was carried out as a cross-sectional, quantitative, field study among a sample of $350 \mathrm{Gen} \mathrm{X}$ and Gen Y professionals, randomly selected from XYZ Bank. Primary data were collected based on a standard measurement scale, through an offline questionnaire survey. Descriptive statistics and the Independent Sample t-test were used to analyze data and coming to conclusions with the aid of SPSS software. There is no significant difference found among Gen X and Gen Y professionals at XYZ Bank in terms of those three work related behaviors; work engagement, career development and teamwork. Further, the importance of a strong corporate culture is emphasized in which generational differences are neutralized up to a significant extent. Hence, it is recommended that the XYZ Bank does customize its people management policies and practices based on the needs and the dynamics of its corporate culture.
\end{abstract}

Keywords: Generation X, generation $Y$, work engagement, career development, teamwork

Copyright: (C) 2020 Pathirage, U. K. and Weerasinghe, T. D. This is an open access article distributed under the Creative Commons Attribution License, which permits unrestricted use, distribution, and reproduction in any medium, provided the original work is properly cited.

Correspondence: dananjaya@kln.ac.lk

ORCID of authors: Weerasinghe, T. D. - https://orcid.org/0000-0001-5096-6696

DOI: http://doi.org/10.4038/kjm.v9i1.7619 


\section{Introduction}

The workforce of an organization is a combination of different generations. Currently, there are five main generations who are working in organizations side by side (Bennet, Pit \& Price, 2012) Those generations are identified and classified as Traditionalists, Baby Boomers, Generation $\mathrm{X}$, Generation $\mathrm{Y}$ and Generation Z (Dur, 2016). Among those five generations, currently the majority is represented by generation $\mathrm{X}$ and generation Y. A generation is a group of people who have born in a same historical time period, and sociocultural context (Mannheim, 1952). Similarly, they share a common set of values, experience and events within a specific time period (Ryder, 1965). However, there are different work related behaviors can be identified among those generations, and those different behaviors result in number of conflicts and consequences directly and indirectly by influencing the productivity of an organization (McGuire et al, 2007).

In any organization, the workforce comprises of different age groups. The age factor of employees is really impacting on their work engagement, career development and teamwork. According to Yagit and Aksy (2015) individuals belong to different generations of age have different experiences, different views, different habits and also different working styles. As reported above, according to literature there are five different groups of generations, which can be identified as Traditionalists, Baby Boomers, Generation X, Generation Y or Millennial and Generation $\mathrm{Z}$ or Super Millennial (Fernandez, 2009). Most of the sources have identified Baby boomers as people who were born between 1943 and 1965 . However, the U.S.A. Census Bureau defines Baby Boomers as who have born between 1946 and 1964 (Tolbize, 2008) and they have been referred to as the 'pig - in - the - python' (Callanan \&
Greenhaus, 2008). According to the U.S.A. Census Bureau, Generation X segment of the population consists of individuals who have born between 1968 and 1979 (Tolbize, 2008). In some cases the upper limit of Generation $\mathrm{X}$ has been as high as 1982 and the lower limit has been as low as 1963 (Karp et al., 2002). This generation was also called as 'baby bust generation' (Tolbize, 2008). According to the National Oceanographic and Atmospheric Association Office of Diversity (2006), generation Y may include individuals who were born between 1978 and 1995. In many sources, the lower limit for Generation Y may be as low as 1978, while the upper limit may be as high as 2002 (Tolbize, 2008). The individuals born after 1996 considered as Generation Z.

The XYZ Bank was started in 1985 and it is a $100 \%$ State own bank. XYZ Bank was started with the main objective of improving the life standards of the rural people by offering credit facilities in an affordable and an accessible manner with the intention of strengthen and develop the rural economy. The XYZ Bank is empowering its customers to start micro, small and medium scales industries, and at the mean time it is empowering the industries such as livestock, fisheries and agriculture that are directly contributing to economic growth of Sri Lanka. The main target of the XYZ Bank is to encourage the women to come up as the entrepreneurs by providing credit facilities.

Other than providing credit facilities, the XYZ Bank has put another step forward to embed the saving habits into blood stream of rural people offering high returns on fixed deposits and savings. As a results of all the above customer engagement bank activities, the XYZ Bank has won over a 06 million loyal customer's base and given 3000 plus employment opportunities in 268 service centers across the country. 


\section{Problem Statement}

There are visible work related differences among the employees of XYZ Bank in different employee categories. Basically, those differences are due to their work related behaviors such as work engagement, career development and teamwork.

When considering the work force of XYZ Bank, it is a combination of different generations as baby boomers, generation $\mathrm{X}$ and generation $\mathrm{Y}$ or millennials. In XYZ Bank most of the baby boomers are working in Special Grade category as Assistant General Managers (AGM), Regional General Managers (RGM), Deputy General Managers (DGM) or General Managers (GM). The generation $\mathrm{X}$ and $\mathrm{Y}$ employees are mostly working as Senior Managers (SM), Branch Managers, Assistant Managers (AM), Management Trainees or Bank Assistants.

The Baby Boomers who are currently working in XYZ Bank will be retired within next five years, and generation $X$ will move up to those positions in future. As a result of that, generation $\mathrm{Y}$ will take the positions which will get vacant. Currently, generation $\mathrm{Z}$ is not employed in this bank, but with the new opportunities coming up in next 05 years would be filled by Generation Z.

Among the employees of XYZ Bank, different work related behaviors have been seriously observed and reported. Hence, this research was initiated to assess and identify; what is the difference of work related behaviors between generation $\mathrm{X}$ and generation $\mathrm{Y}$ employees working in XYZ Bank. As work related behaviors; work engagement, career development, and teamwork were considered which are highly recommended in the extant literature as researchable areas further with respect to those two generations at work.
Through this study, researchers intended to achieve the following objectives.

\section{Objectives of the Study}

i. To assess and identify whether generation X significantly differ from generation $\mathrm{Y}$ in their attitude towards work engagement.

ii. To assess and identify whether generation X significantly differ from generation $\mathrm{Y}$ in their attitude towards career development.

iii. To assess and identify whether generation $\mathrm{X}$ significantly differ from generation $\mathrm{Y}$ in their attitude towards teamwork.

Results of the current study would really help to plan and implement the diversity management strategies which in turn will improve organizational productivity. Further, it will provide more beneficial information to company policy makers and trainers to fix their policies and trainings to achieve the objectives of the bank in a profitable manner in a peopleoriented diverse culture.

The rest of this paper proceeds as follows: In the following section, literature pertaining to the constructs followed by relevant theoretical explanations and empirical findings are reviewed. The third section outlines the hypotheses development. Next, the methodology of the current study is outlined and the findings are also presented. In the fourth section, the findings are discussed, delineating the practical implications along with the limitations and directions for future research. The final section presents the conclusion and the recommendations.

\section{Literature Review}

Sociologists have studied different generations from different perspectives. According to Kertzer (1983) a generation is a group of people who have mutual characteristics with related to each other. 
According to Johnson and Johnson (2010) a generation is referred as a group of individuals who were born in similar years and they have common in thoughts, values, behaviors, beliefs, attitudes and experience, and those common factors of generations create culture, economy and political views for the society at the time that they live (Guilloti-Soulez \& Soulez, 2014). Other than that, every generation has their own unique structure based on values, belief and behaviors (Giancola, 2006) and this generational uniqueness highly affect the performance of individuals at work. On the other hand having a diversity of age in an organization or workplace is beneficial because the different generations have different talent and skill diversity (Hansen $\&$ Leuty, 2012). The following section of the paper explains various work related behavioral differences among those five generations.

\section{Traditionalists}

Traditionalists are the oldest generation in the workplace and most of them are already retired now. The traditional generation is known as the silent generation; the veterans; the mature generation, and the greatest generation. Individuals of this generation have born before 1945 (Tolbize, 2008). Members of this generation are very loyal, educated, highly committed towards collaboration and teamwork, but fear of risk (Tolbize, 2008). According to Jenkins (2007) they have developed their communication skills. At their working environment, they maintain the uniformity and consistency of work; the decisions are made based on past experience, show command-andcontrol leadership and highly hierarchical structure-oriented in working organizations (Tolbize, 2008). They like to continue top management system with horizontal structures in an organizational hierarchy. They are very in-detail and thorough in their works, hardworking and loyal but really resistance to change and not comfortable with conflicts (Zemke, Raines \& Filipczak, 1999).

\section{Baby Boomers}

According to the generation classification baby boomers are the second generation. They have born between 1946 and 1960 (Holton and Fraser, 2015). Some of the sources identified their born year as 1943 to 1965 (Tolbize, 2008). According to U.S. Census Bureau, they have born between 1946 and 1964 (Tolbize, 2008). The name of pig-in-the-python is also referred for baby boomers (Tolbize, 2008). They are very loyal to their bosses, respecting to direction and align with that, hardworking and highly dedicated for their work (Scripta, 2016). Further, they are excellent in social networking having excellent social skills. But, their technical skills are poor (Scripta, 2016). They were the individuals who started 60 hours working time per week and it provides the evidence for their level of hard working (Holton \& Fraser, 2015). Their first priority is identified as the job, and the personal lives come the second (Holton \& Fraser, 2015). They like to work as a team, and most of the decisions are taken as a team (Tolbize, 2008). They expect recognition for their achievements, and they are highly result-oriented (Zemke et al., 1999). They hate conflicts and highly expect their job security balanced with the personal growth (Tolbize, 2008).

\section{Generation X}

Generation X (Gen X) members have born between 1965 and 1975 (McShane \& Von-Glinow 2000), and they are named as Post baby - Boomers, Baby - Busters, Slackers, Hackers, Thirteeners, Grungers, 
and the Repair Generation. Gen X is the generation which led the culture change of many organizations through new approaches. Gen X employees are very collaborative or accustomed to working in teams, well educated, high entrepreneurial skills, less hierarchical, like to change their job frequently, good in technological skills, poor conscious of formalized rules and regulations, and like to find a career which provides work life balance (Burke, 1994).

Moreover, generation $\mathrm{X}$ employees are good in accomplishing a balance among work and the life compared to the previous generations (Jenkins, 2007; Karp et al, 2002). Also, Gen $X$ employees are more liberated, self-reliant and autonomous than their predecessors (Jenkins, 2007; Zemke et al., 2000). However, Gen $X$ is not much faithful to their respective employers or organizations (Bova \& Kroth, 2001; Karp et al, 2002; The National Oceanographic and Atmospheric Association Office of Diversity, 2006). But, they possess solid sentiment of loyalty to their family and friends (Karp et al., 2002). They give priority for continuous learning and skills development (Bova \& Kroth, 2001). Gen $\mathrm{X}$ usually possess solid technical competencies and skills (Zemke et al., 2000) and more results driven (Crampton \& Hodge, 2006). To motivate the employees of generation $\mathrm{X}$, money is not a must but if the money is absent, it may drive them to become demotivated (Karp et al., 2002). This generation is really flexible to revolutions (Zemke et al., 2000), and elastic timetables are preferred by them (Joyner, 2000). Employees belong to Gen $\mathrm{X}$ are typically creative (The National Oceanographic and Atmospheric Association Office of Diversity, 2006). They like to work as teams. Hence, they are considered good team players than baby boomers (Karp et al., 2002).

\section{Generation Y}

Gen Y employees are identified as highly self-absorbed and self-confident (Pew Research Center, 2007). But, they are lacking the loyalty and work ethics (Marston, 2009). Gen Y features are more complicated and potentially unsettled in workplace relations with individuals of other cohorts, accordingly destructively affecting co-workers and organizational processes (Alsop et al. 2009; McGuire et al. 2007). To succeed and entirely exploit the exclusive aptitudes of Gen Y, they are required to be alert on their policies and rules (Gursoy et al. 2008). However, they have admirable traits from the perspective of organizations, including the diversity orientation compared to past generations, high capabilities in advanced communication and information technology, ability to identify problems and really comfortable to work as teams than past generations (Howe \& Strauss 2000; Gorman et al. 2004; Tapscott 1998; Zemke et al. 2000).

Employees belong to generation $\mathrm{Y}$ have a sharp knowledge on ICT (Niemiec, 2000) and very familiar with technology (Kersten, 2002). Among all the generations they are identified as the most adaptable generation to changes (Jenkins, 2007). They seek flexibility (Martin, 2005), like to be independent, always desire a balanced life (Crampton \& Hodge, 2006), and multi-takers (The National Oceanographic and Atmospheric Office of Diversity, 2006). They are really demanding themselves (Martin, 2005), and also they are the most confident generation (Glass, 2007). However, they are very poor in process focused (Crampton \& Hodge, 2006). 
When earlier generations are retired, Gen $\mathrm{X}$ will be the experienced employees and managers in the organizations, and Gen $Y$ continues entering into positions that Gen $\mathrm{X}$ held previously (Smola \& Sutton, 2002). Those two generations will be working together closely for at least next 10 to 20 years.

\section{Generation Z}

The newest generation is the generation $\mathrm{Z}$ and they are also referred as the postmillennials, Generation 2020, and 0 Generation (Holton \& Fraser, 2015). Generation $\mathrm{Z}$ individuals are born between 1995 and 2010 and they do most of the things differently from baby boomers, Generation X and Generation Y (Scripta, 2016). This generation highly familiarizes with technology, mobile phones, short messages, internet or worldwide web, IPad, mp3 players, PADs, YouTube and other new technologies (Kapil \& Roy, 2014).

Generation $\mathrm{Z}$ individuals are highly selfconfident, more social and active team players. Their team spirit is high in the work environment (Ozkan \& Solmaz, 2015) and well aware about the new technology. They are very creative and innovative (Scripta, 2016). They like to grow fast as professionals and willing to get 'hands-on' and 'minds-on' learning experience (Scripta, 2016). They look for competitive salaries and benefits compared to other generations. If they don't get that, they never think twice to move to another employment opportunity which is offering good benefits and better packages (Scripta, 2016).

This generation is well integrated with information technology and internet. Hence, their electronic communication skills like in e-mails, chats and Skype are well polished. Other than that they are highly project-oriented, ready to move with targets and achievements (Scripta, 2016). Also, they try to maintain a virtual life and a virtual image in virtual communities. It means they value the virtuality than reality.

\section{Behavioral Differences among Generations}

Globally current labor market consists of different generations as baby boomers, generation $\mathrm{X}$, generation $\mathrm{Y}$ and newly entering generation; Gen $\mathrm{Z}$. The labor force of those generations represents different age categories and different values they have, beliefs, attitudes, working styles, communication skills and management styles towards work and the organization. Out of those generations baby boomers are the oldest representatives of the labor market, and they have entered to the labor force in between 7 th decade and the middle of 9th decade. Currently, they are undergoing the last few years of their career. But, still they are playing a big role in the labor force (Valickas, 2017).

Baby boomers are loyal to their bosses and organizations up to a certain extent, but not like their superior generation (Valickas, 2017). Meantime, generation X is loyal to their profession rather than to work place or an organization (Valickas, 2017). And also the dedication of generation $\mathrm{X}$ to their employer is relatively low compared to the traditional generation and baby boomers (Valickas, 2017). The behavior of less loyalty towards organization and dedication towards the work are the results of their parents' influence. Because most of their parents have realized that their loyalty to organization has failed to save their jobs (Tolbize, 2008). Hence, generation $\mathrm{X}$ gives the first priority to their personal life than the work life (Valickas, 2017). 
In many aspects, generation $\mathrm{Y}$ and generation $\mathrm{X}$ have similar work related behaviors. Generation Y is highly loyal to their career, not the organization. Hence, they are not working long time in an organization and they highly concern about their current position (Parry \& Urwin, 2011). Generation Y become loyal to their job role or project first, and then their working organizations. Generation $\mathrm{Y}$ can be motivated by giving new job tasks, providing professional training and development opportunities parallel with financial benefits (Valickas, 2017).

The older generations (Traditionalists and Baby boomers) had high interest for training that related to their current job role. But, younger generations (Gen $\mathrm{X}$ and Gen Y) like to attend trainings which are related to management and leadership (Tolbize, 2008; Parry \& Urwin, 2011). It is found that $70 \%$ of the silent generation workers would like to stay rest of their life in the same workplace. The Baby boomers $65 \%$, Generation X $40 \%$ and Generation $\mathrm{Y} 20 \%$ are aligning with this perception (Tolbize, 2008).

Gen $\mathrm{X}$ is pessimistic and poor in believing that climbing the ladders to success in future (Cole et al., 2002) and giving small chance for promotions and opportunities motivate Gen X employees to staying with the same employer (Weston, 2006). Hence, this generation couldn't get proper career growth and they are not loyal to their employers also (Weston, 2006).

On the other hand, Gen Y is optimistic and they like to tackle tasks by expecting the success (Cole et al., 2002). They like to get feedbacks immediately from their superiors in regular basis, not just once or twice a year. Thus, Gen Y employees are impatient (Sujansky, 2004; Wood, 2006). This is the strategy that they use to get an idea about the place where they are standing on, and where they are going from their career. Gen Y members are identified as educated and they are open to accept challenges. As a result of that, they set high career goals (Kovarik, 2008).

Both Gen $\mathrm{X}$ and Gen $\mathrm{Y}$ have positive understanding about the spirit and value of teamwork. But, the only different point is their individual concept (Mirza, 2018). Because of the difference of individual concept, there is a clear difference between Gen X and Gen Y with respect to teamwork. Most of Gen X members are poor team players and like to do things individually. But, they give high priority for their personal relationships (Patterson, 2007). As per Patterson (2007) Gen $X$ members are showing independent characteristic, poor in patience in teams and come together. Apart from that Gen X really loves to do their works individually and which is called as 'conveyer-belt concept' of teamwork (Mirza, 2018). The meaning of that concept is, the Gen $\mathrm{X}$ likes to perform their job role in their own style, in an engaged work project alone (Mirza, 2018). Therefore, Gen X employees are very efficient and productive even smaller in numbers, when they are allowed to work individually and independently (Mirza, 2018).

Gen Y members are good in teamwork and they have close bonds with their friends (O'Reilly, 2000). According to the UAO (2006), Gen Y members are above the average of their teamwork capabilities. Gen $Y$ members prefer to use new technology while they are working as a team (Mirza, 2018). They highly prefer to use teleconferencing, cloud sharing and group chats to make easy of their teamwork (Mirza, 2018). When Gen Y members work as a team, the size of it does not matter. What matters is the value given for their opinions and who heard 
their voice in the team (Mirza, 2018). To get the optimum outcome from Gen Y through teamwork, an organization should facilitates the teamwork in an effective way (Fernandez, 2009).

As the current study was carried out as a cross-sectional, quantitative, but descriptive field study, no conceptual framework is developed. Because any relationship is not hypothesized to be shown in a framework. Instead, for the assumed differences, based on literature and the evidence observed in XYZ Bank, following three hypotheses were advanced.

\section{Hypotheses of the Study}

Building on the aforementioned evidence, the below hypotheses were advanced to be tested in the current study.

H1: Work engagement is significantly different among generation $\mathrm{X}$ and generation $\mathrm{Y}$ employees.

H2: Career development is significantly different among generation $\mathrm{X}$ and generation $\mathrm{Y}$ employees.

H3: Teamwork is significantly different among generation $\mathrm{X}$ and generation $\mathrm{Y}$ employees.

\section{Population, Sample and the Sampling Technique}

Currently, 2347 employees are working in $\mathrm{XYZ}$ Bank as permanent employees. Among them 16\% are baby boomers, 39\% represents generation $X$, and $45 \%$ of them represent generation $\mathrm{Y}$.

Out of 2347 employees working in the XYZ Bank across the country, 350 were selected randomly to be included in the study sample. The sample calculation table (with $\mathrm{CI}=0.95$ ) was used to determine the sample size. Stratified simple random sampling technique was used to select individual employees to the sample. Initially, researchers identified Gen X employees and Gen Y employees separately based on their birth year using the information obtained from the Human Resource Information System. Then, distributed 380 printed questionnaires out of which 362 questionnaires were returned. The most suitable and completed 350 responses were considered for the analysis.

\section{Data Collection and Analysis}

Primary data were collected through a standard measurement scale/s. The survey questionnaire was adopted based on the measurement scales developed by Glass (2007); Hansen and Leuty (2012), and Mood (2006). To assess the work related behavior of work engagement, 10 items were given (adopted form Glass, 2007). Similarly, 12 items for career development (adopted from Mood, 2006) and 12 items for teamwork (adopted from Hansen \& Leuty, 2012) were given. Additionally, two demographic questions were inserted at the beginning of the questionnaire to recognize the gender and the service period of the respondent. Questionnaires were separately coded to identify the generation. Validity and the reliability of those adopted measurement scales were ensured through a pilot survey conducted among a sample of 35 respondents. The collected data were analyzed using Statistical Package for Social Sciences (SPSS) by employing descriptive statistics and the independent sample t-test.

\section{Results and the Discussion}

There were $49 \%$ of males and $51 \%$ of females included in the sample representing the both generations. Further, $54 \%$ of Gen X professionals and $46 \%$ of 
Gen Y professionals were included in the final sample. Moreover, in the sample $75 \%$ of the employees have more than 10 years of a working experience while $21 \%$ of them have 05 to 10 years of a working experience. Only $04 \%$ of the employees have 1 to 5 years of a working experience at XYZ Bank.

\section{Validity and Reliability Statistics}

The reliability was ensured through the Cronbatch's Alpha coefficient of internal consistency. According Castrllo and Osborne (2005) to be reliable the Alpha value should be greater than 0.7 . As depicted in table 01, Alpha values obtained for all the constructs are above 0.7 , and hence, it is statistically proven that the measurement scales used are reliable, and suitable for further inferential analyses.

Table 01: Reliability Statistics

\begin{tabular}{|l|c|c|}
\hline \multicolumn{1}{|c|}{ Variable/s } & $\begin{array}{c}\text { Cronbach's } \\
\text { Alpha }\end{array}$ & $\begin{array}{c}\text { No. of } \\
\text { Items }\end{array}$ \\
\hline $\begin{array}{l}\text { Work } \\
\text { Engagement }\end{array}$ & 0.800 & 16 \\
\hline $\begin{array}{l}\text { Career } \\
\text { Development }\end{array}$ & 0.764 & 13 \\
\hline Teamwork & 0.701 & 07 \\
\hline
\end{tabular}

Source: Analyzed Data, 2019

Table 02: Validity Statistics

\begin{tabular}{|l|c|c|}
\hline \multicolumn{1}{|c|}{ Variable/s } & $\begin{array}{c}\text { ESSL } \\
\text { Cumulative } \\
\%\end{array}$ & $\begin{array}{c}\text { Lowest } \\
\text { FL } \\
\text { Value }\end{array}$ \\
\hline $\begin{array}{l}\text { Work } \\
\text { Engagement }\end{array}$ & 59.703 & 0.337 \\
\hline $\begin{array}{l}\text { Career } \\
\text { Development }\end{array}$ & 63.244 & 0.381 \\
\hline Teamwork & 56.858 & 0.338 \\
\hline
\end{tabular}

Source: Analyzed Data, 2019

The construct validity of the questionnaire was assessed using the Exploratory Factor Analysis (EFA). The results of EFA analysis are elaborated in table 02 .
According Castrllo and Osborne (2005) to be statistically valid for the measurement scales, Extraction Sums of Squared Loadings-Cumulative (ESSL-Cum\%) should be greater than $50 \%$, and the Lowest Factor Loading Value (Lowest FL) should be greater than 0.30 in EFA. As, depicted in table 02, those two baseline conditions have arrived in the current study ensuring the construct validity of all the measurement scales used in data collection.

\section{Independent Sample t-test}

According to the table 03 (Appendix A) significance value of Levene's Test for Equality of Variances of work engagement is 0.667 which is greater than $0.05(0.667>0.05)$. Therefore, the variance for Gen X and Gen Y is assumed to be not equal with respect to work engagement.

With regards to above conclusion the equal variances not assumed row of table 03 (Appendix A) was used to test the hypothesis 01 . The sig. (2-tailed) value of work engagement is 0.061 which is greater than the accepted sig. value of 0.05 . Since the sig. value is greater than 0.05 , the H1 is statistically not accepted. Hence, it could be statistically claimed that there is no significant difference between generation $\mathrm{X}$ and generation $\mathrm{Y}$ professionals in XYZ Bank with respect to their work engagement behavior.

The sig. value for Levene's Test for Equality of Variances of career development is 0.206, which is also greater than 0.05 . Similarly, for the construct; teamwork the coefficient of the Levene's Test for Equality of Variances is 0.207 , which is greater than 0.05 . Hence, it can be concluded that the variances for Gen $\mathrm{X}$ and Gen $\mathrm{Y}$ is not equal with respect to the career development behavior and teamwork. 
So, the equal variance not assumed rows of table 03 (Appendix A) were used to test $\mathrm{H} 2$ and $\mathrm{H} 3$. The sig. (2-tailed) values of career development is 0.804, and teamwork that is 0.574 . Both sig. values are greater than 0.05 . Hence, the hypotheses; $\mathrm{H} 2$ and $\mathrm{H} 3$ are not accepted. Therefore, it is statistically justified coming to a conclusion that there is no significant difference exist among two generations in terms of career development and teamwork.

\section{Discussion of Findings}

According to the findings of the independent sample t-test, it is found that there is no significant difference between Gen $\mathrm{X}$ and Gen $\mathrm{Y}$ in terms of work engagement. However, in the extant literature, researchers have contradictory views on this concern. Some researchers stated that there is a significant difference between Gen X and Gen Y, whereas some have found there is no significant difference. Drake (2012), Kunreuther (2003), Dwyer (2009), Pitt-Catsouphes and Matz-Costa (2009), Robinson, Perryman and Hayday (2004) suggested that organizations should have customized strategies to improve work engagement of different generations. In sub-Saharan Africa, Gen Y have a higher level of work engagement than Gen X (Maurer, 2013). In Australia, the two generations of Baby Boomers and Gen Y are identified as the most work engaged (Australian Public Service Commission, 2012). In South Africa, Gen Y employees are identified as the cohort having the highest degree of work engagement (Kenexa, 2012). Those research findings emphasize the likelihood of regional and cultural influences that affect the work engagement among different generations. Hence, the cultural and regional differences could be an influencing factor regarding generational difference in work engagement. Apart from that, the research sample represented employees those who are employed more than 5 years in XYZ Bank. Therefore, they might be more adapted to the organizational culture so far, which might have reduced the generational difference in work engagement.

In independent sample t-test it is found that there is no significant difference between Gen X and Gen Y in terms of their career development intentions and the behavior. However, existing literature provide an opposite view. According to the extant literature earlier generations usually concentrated on career development in a different way than their successors. Generations such as baby boomers and Gen X believe that they will have career development opportunities based on their service period whereas later Gen $X$ believe that career development will be available, if they pursue more opportunities (Grubb, 2016). Hence, it was concluded that there is a significant difference between generations in terms of career development. But, this study provides an opposite argument compared to the findings of other researches. As mentioned above, the results of the present study might be different due to the contextual differences.

Similarly, for the third research parameter; teamwork also, findings of the independent sample t-test depicted that there is no significant difference between Gen X and Gen Y. According to Mirza (2018) each generation have their own individual concepts. Those concepts grow as generations evolve. As Mirza (2018) stated, earlier generations such as the silent generation was not individualistic, whereas later generations such as Gen $\mathrm{X}$ and $\mathrm{Y}$ are more individualistic. Further, 
later generations are more concerned about their individual performances than overall team performance. With the above finding it is evident that later generations are more concerned about individual achievements rather than team achievements. Patterson (2007) stated that Gen X members concentrate more on their personal achievements and relationships, whereas Gen Y members pay rather less concern on their individual performances and achievements. Further, he stated that Gen X employees show poor patience compared to their predecessors resulting lower teamwork among themselves and with other generations.

\section{Conclusion}

The current study concludes declaring that, in XYZ Bank, there is no significant difference among Gen $X$ and Gen Y professionals in terms of three basic work related behaviors; work engagement, career development, and teamwork. Further, the contextual differences and length of the service period of employees are emphasized in the current study which neutralize generational differences at work up to a significant extent. However, the present study came up with a different finding than in existing literature which was different in the contextual format. As it has mentioned repeatedly, the reason for this difference in the findings might be caused by the contextual differences. Employees in XYZ Bank might have absorbed the culture of the bank to the extent where they forgot their generic generational differences.

\section{Recommendations}

Findings of this research enable the researchers to provide some recommendations to the organization to manage multi-generational work force effectively and efficiently. Based on the conclusion of the study, cultural background of XYZ Bank plays a significant role in diluting differences between Gen X and Gen Y. Hence, the organization has the ability to manage the workforce using the same approaches and methods.

When it comes to work engagement, the bank can appoint employees to positions that will enable to perform better making them more engaged. Further, the superiors should be instructed to lead their subordinates regularly in every work aspect. The constant feedback regarding each individual's performance is also important in improving the work engagement. Moreover, they should be given effective trainings to develop themselves, which in turn would increase the work engagement.

In terms of career development, XYZ Bank can follow a few measures to improve this work related attitude by providing career counselling opportunities to high performing employees. Results of annual performance evaluation can be used meaningfully to provide training and development opportunities, which will help them to have better career development opportunities in future. Further, the bank can adopt 'nine-box grid' to identify employees with the potential and manage the succession plan of the bank.

The bank can promote a culture in which trusting each other is common through effective communication. Further, the bank can demote a culture where disagreements are criticized. Moreover, the bank can restore the divisions and departments in micro - teams with four to eight members and provide them goals, which will unite them and encourage them to act as a team.

\section{References}

Alsop, R. (2008). The trophy kids group up: How the Millennial Generation is 
shaping up the Workplace. San Francisco: Jossey Bass.

Bennett, J., Pitt, M., \& Price, S. (2001). Understanding the impact of generational issues in the workplace. Journal of Workplace Facilities, 30(8), 278-288. https://doi.org/10.1108/02632771211220 086

Bova, B., \& Kroth, M. (2001). Workplace Learning and Generation X. Journal of Workplace Learning, 13, 57-65. https://doi.org/10.1108/13665620110383 645

Burke, J. R. (1994). Generation-X: Measures, Sex and Age Differences. Psychological Reports, 74(2), 555-663. https://doi.org/10.2466/pr0.1994.74.2.555

Callanan, G., \& Greenhaus, J. (2008). The baby boom generation and career management: A call to action. Advances in Developing Human Resources, 10, 70-85. https://doi.org/10.1177/15234223073101 13

Catteeuw, F., Flynn, E., \& Vonderhost, J. (2007). Employee engagement: Boosting productivity in turbulent times. Organization Development Journal, 25(2), 151-157.

Center, P. R. (2007). How young people view their lives, future, and politics: A portrait of Generation Next, (2 ed.), 4356.

Cole, G., Lucas, L., \& Smith, R. (2002). The Debut of Generation $\mathrm{Y}$ in the American Workforce. Journal of Business Administration, 1(2), 1-10.

Crampton, S., \& Hodge, J. (2006). The supervisor and generational differences. Organizational Culture, Communications and Conflict, 11, 19-22.

Galpin, M., Linley, A., Page, N., \& Stairs, M. (2006). Retention on a knife edge: The role of employee engagement in talent management. Selection \& Development Review, 22(5), 19-23.

Glass, A. (2007). Understanding generational differences for competitive success. Industrial and Commercial Training, $\quad 39, \quad 98-103$. https://doi.org/10.1108/00197850710732 424

Gorman, P., Nelson, T., \& Glassman, A. (2004). The Millennial generation: A strategic opportunity. Organizational Analysis, 12(3), 255-270.

Guillot-Soulez, C., \& Soulez, S. (2014). On the heterogeneity of Generation Y job preferences. Employee Relations, 36(4), 319-332. https://doi.org/10.1108/ER-072013-0073

Hansen, J., \& Leuty, M. (2012). Work values across generations. Journal of Career Assessment, 20(1), 34-52. https://doi.org/10.1177/10690727114171 63

Howe, N., \& Strauss, W. (2000). Millennials rising. New York: Vintage Books.

Jenkins, J. (2007). Leading the four generations at work. American Management Association, 23-71.

Jiri, B. (2016). The Employees of Baby Boomers Generation, Generation X, Generation $\mathrm{Y}$ and Generation $\mathrm{Z}$ in Selected Czech Corporations as Conceivers of Development and Competitiveness in their Corporation. Journal of Competitiveness, 8(4), 105123. https://doi.org/10.7441/joc.2016. 04.07

Johnson, M., \& Johnson, L. (2010). Generations, Inc. New York: AMACOM.

Joyner, T. (2000). Gen X-ers focus on life outside the job fulfillment. Retrieved on May 15, 2019, from The Secured Lender May/ Jun: http:// findarticles.com. 
Kapil, L., \& Roy, A. (2014). Critical Evaluation of Generation $\mathrm{Z}$ at Workplaces. International Journal of Social Relevance \& Concern, 2(1), 10-14.

Karp, H., Fuller, C., \& Sirias, D. (2002). Bridging the boomer Xer gap. Creating authentic teams for high performance at work. Palo Alto: Davies Black Publishing.

Kertzer, D. (1983). Generation as a sociological problem. Annual Review of Sociology, $\quad 9, \quad 125-149$. https://doi.org/10.1146/annurev.so.09.08 0183.001013

Kovarik, M. (2008). How to Engage Gen Y. Inside Supply Management, 2(1), 1012.

Scripta, L. (2016). The Current Generations: The Baby Boomers, X, Y and $\mathrm{Z}$ in the Context of Human Capital Management of the $21^{\text {st }}$ Century in Selected Corporations in the Czech Republic. Tomas Bata University in Zlín, 9(2), 102-110.

Mannheim, K. (1952). The sociological problem of generations. Essays on the Sociology of Knowledge, 3(1), 276-322.

Marston, C. (2007). Motivating the 'what's in it for me?' workforce: Manage across the generational divide and increase, John Willey and Sons, Inc. USA. 23-131.

Marston, C. (2009). Myths about Millennials: Understand the myths to retain Millennials. Bus Psychology (2010) 25:225-238.

https://doi.org/10.1007/s10869-0109172-7

Martin, C. (2005). From high maintenance to high productivity. What managers need to know about Generation Y? Industrial and Commercial Training, 37, 39-44. https://doi.org/10.1108/00197850510699 965
McGuire, D., Todnem, R., \& Hutchings, K. (2007). Towards a model of human resource solutions for achieving intergenerational interactions in organizations. Journal of European Industrial Training, 31(8), 592-608.

McShane, S., \& Von Glinow, M. (2000). Organizational behavior: Emerging realities for the workplace revolution. Boston: McGraw-Hill.

Mood, G. (2006). Recognizing the generational divide: When $\mathrm{x}$ meets $\mathrm{y}$ at the tribal college. Tribal College Journal, 4, 24-25.

Niemiec, S. (2000). Finding common ground for all ages. Security Distributing and Marketing, 11(2), 30-31.

O'Reilly, B. (2000). Meet The Future. Fortune, 144-168.

Ozkan, M., \& Solmaz, B. (2015). The Changing Face of the Employees Generation $\mathrm{Z}$ and Their Perceptions of Work (A Study Applied to University Students). Procedia Economics and Finance, 26(1), 476-483. https://doi.org/10.1016/S2212-

5671(15)00876-X

Parry, E., \& Urwin, P. (2011). Generational Differences in Work Values: A Review of Theory and Evidence. International Journal of Management Reviews, 13(1), 79-96. https://doi.org/10.1111/j.14682370.2010.00285.x

Ryder, N. (1965). The cohort as a concept in the study of social change. American Sociological Review, 843-861. https://doi.org/10.2307/2090964

Smith, G. (2013). Managing Generations in the Workplace. Journal of Competitiveness, 8(1), 90-106.

Smola, K., \& Sutton, C. (2002). Generational differences: Revisiting generational work values for the new 
Pathirage U. K., Weerasinghe T. D., KJM, 2020, 09 (01)

millennium. Journal of Organizational Behavior, 23, 363-382. https://doi.org/10.1002/job.147

Tolbiz, A. (2018). Generational Differences in the Workplace. Journal of Managerial Psychology, 23(8), 23-46. https://doi.org/10.5430/ijba.v6n2p106

Weston, M. (2006). Integrating generational perspectives in nursing. Journal of Issues in Nursing, 1(2), 12-22.

Yigit, S., \& Aksay, K. (2015). A Comparison between Generation $\mathrm{X}$ and Generation $\mathrm{Y}$ in Terms of Individual Innovativeness Behavior: The Case of Turkish Health Professionals. International Journal of Business Administration, 6(2), 65-73.

Zemke, R., Raines, C., \& Filipczak, B. (1999). Generations at work: Managing the clash of veterans, boomers, Xers, and nexters in your workplace. New York: AMACOM. 


\section{Appendices}

\section{Appendix A}

Table 03: Results of the Independent Sample t-test

\begin{tabular}{|c|c|c|c|c|c|c|c|c|c|c|}
\hline & \multicolumn{2}{|c|}{$\begin{array}{c}\text { Levene.'s Test } \\
\text { for Equality of } \\
\text { Variances } \\
\end{array}$} & \multicolumn{7}{|c|}{ T-test for Equality of Means } \\
\hline & & \multirow{2}{*}{$\mathrm{F}$} & \multirow{2}{*}{ Sig. } & \multirow{2}{*}{$\mathrm{T}$} & \multirow{2}{*}{$\mathrm{df}$} & \multirow{2}{*}{$\begin{array}{l}\text { Sig. (2- } \\
\text { tailed) }\end{array}$} & \multirow{2}{*}{ Mean Diff. } & \multirow{2}{*}{$\begin{array}{l}\text { Std. Error } \\
\text { Diff. }\end{array}$} & \multicolumn{2}{|c|}{$\begin{array}{c}95 \% \text { Confidence Interval } \\
\text { of the Difference }\end{array}$} \\
\hline & & & & & & & & & Lower & Upper \\
\hline \multirow{2}{*}{ WE } & $\begin{array}{l}\text { Equal. Variances } \\
\text { Assumed }\end{array}$ & .174 & .677 & 1.910 & 88 & .059 & .18082 & .09465 & -.00728 & .36892 \\
\hline & $\begin{array}{l}\text { Equal Variances } \\
\text { not Assumed }\end{array}$ & & & 1.898 & 82.800 & .061 & .18082 & .09526 & -.00865 & .37028 \\
\hline \multirow{2}{*}{$\mathrm{CD}$} & $\begin{array}{ll}\text { Equal } & \text { Variances } \\
\text { assumed } & \end{array}$ & 1.627 & .206 & .243 & 88 & .809 & .02309 & .09498 & -.16567 & .21184 \\
\hline & $\begin{array}{l}\text { Equal Variances } \\
\text { not assumed }\end{array}$ & & & .249 & 87.498 & .804 & .02309 & .09286 & -.16146 & .20764 \\
\hline \multirow{2}{*}{ TW } & $\begin{array}{ll}\text { Equal } & \text { Variances } \\
\text { assumed } & \end{array}$ & 1.615 & .207 & .558 & 88 & .578 & .04480 & .08025 & -.11467 & .20427 \\
\hline & $\begin{array}{l}\text { Equal Variances } \\
\text { not assumed }\end{array}$ & & & .564 & 87.507 & .574 & .04480 & .07949 & -.11319 & .20279 \\
\hline
\end{tabular}

Source: Analyzed Data, 2019 